\title{
Predicting India Volatility Index: An Application of Artificial Neural Network
}

\author{
Gaurav Dixit \\ Indian Institute of Management \\ Indore, Indore \\ Madhya Pradesh, India
}

\author{
Dipayan Roy \\ Indian Institute of Management \\ Indore, Indore \\ Madhya Pradesh, India
}

\author{
Nishant Uppal \\ Indian Institute of Management \\ Indore, Indore \\ Madhya Pradesh, India
}

\begin{abstract}
Forecasting has always been an area of interest for the researchers in various realms of finance especially in the stock market e.g. stock index, return on a stock, etc. Stock market volatility is one such area. Since the inception of implied volatility index (VIX) by the Chicago Board of Options Exchange (CBOE) in 1993, VIX index has generated a lot of interest. This study examines the predicting ability of several technical indicators related to VIX index to forecast the next trading day's volatility. There is a wide set of methods available for forecasting in finance. In this study, Artificial neural network (ANN) modeling technique has been employed to forecast the upwards or downwards movement in next trading day's volatility using India VIX (a volatility index based on the NIFTY Index Option prices) based indicators. The results of the study reveal that ANN models can be real handy in forecasting the downwards movement in VIX. The knowledge about a more probable downwards movement in volatility might be significant value add for the investors and help them in making decisions related to trading.
\end{abstract}

\section{General Terms}

Artificial Neural Network (ANN), Forecasting

\section{Keywords}

Artificial Neural Network, India VIX, Forecasting, NIFTY Index options

\section{INTRODUCTION}

The need to measure the market volatility was realized after the global stock market crash in 1987. The Circuit Breaker mechanism introduced by the New York Stock Exchange (NYSE) is believed to have fostered the idea of developing the VIX (Xin, 2011). The Volatility Index was first developed by the Chicago Board Options Exchange (CBOE) on the basis of the implied volatility of the S\&P 100 index options in the year 1993 .

After a series of developments and improvements of the initial model, the CBOE together with Goldman Sachs came up with an evolved model of the VIX which could measure the expected volatility and thus would be of immense help to financial analysts, risk managers and volatility traders (The CBOE Volatility Index-VIX). The evolved model of the VIX estimated the expected volatility on the basis of the average weighted price of SPX puts and calls over a wide range of strike prices.

The utility of the model increased through manifolds when the CBOE launched VIX options in 2006. The rationale for the development of this financial instrument was due to the negative correlation of Volatility with the returns in the stock markets.
India VIX is a volatility index based on the index option prices of NIFTY. The computational procedure of India VIX includes the best bid and asks quotes of the out-of-the-money near and mid-month NIFTY option contracts which are traded on the F\&O segment of NSE (White Paper on India VIX). India VIX indicates the investor's perception of the market's volatility in the near term. The index represents the expected market volatility over the next 30 calendar days. An increase or decrease in the India VIX values is related to a corresponding increase or decrease in the expected volatility and vice-versa.

The computational Formula for the India VIX is as follows:

$\sigma^{2}=\frac{2}{T} \sum \frac{\Delta K_{i}}{K_{i}^{2}} e^{R T} Q\left(K_{i}\right)-\frac{1}{T}\left[\frac{F}{K_{0}}-1\right]^{2}$

Where

$\sigma \quad$ India VIX/100 or India VIX $=\sigma \times 100$

$\mathrm{T} \quad$ Time to expiration

$\mathrm{K}_{\mathrm{i}} \quad$ Strike price of $\mathrm{i}^{\text {th }}$ out-of-the money option, a call if $\mathrm{K}_{\mathrm{i}}>\mathrm{F}$ and a put if $\mathrm{K}_{\mathrm{i}}<\mathrm{F}$

$\Delta \mathrm{K}_{\mathrm{i}} \quad$ Interval between strike Prices- half the distance between strikes on either side of $K_{i}$,

$$
\Delta \mathrm{K}_{\mathrm{i}}=\left(\mathrm{K}_{\mathrm{i}+1}-\mathrm{K}_{\mathrm{i}-1}\right) / 2
$$

$\mathrm{R}$ : Risk-free interest rate to expiration

$\mathrm{Q}\left(\mathrm{K}_{\mathrm{i}}\right) \quad$ : Midpoint of the bid ask quote for each option contract with strike $\mathrm{Ki}$

F $\quad$ : Forward index taken as the latest available price of NIFTY future contract of corresponding expiry

$\mathrm{K} \quad$ : First strike below the forward index level, F.

VIX index is regarded as the premier benchmark of stock market volatility by investors around the world (Degiannakis \& Floros, 2010). According to Degiannakis (2008) and Degiannakis \& Floros (2010), implied volatility is an accurate predictor of next day's volatility. Previously, many models such as GARCH and ARFIMA have been studied to forecast volatility and negative results have been reported (Blair et al., 2001; Degiannakis, 2008). There is lack of research studies which have investigated the forecasting ability of Artificial neural network (ANN) models in the area of volatility forecasting. ANN models are considered to be one of the strong predictive data mining techniques. In ANN, a set of explanatory variables are used to explain a target variable without making any structural or linear relationship assumption between the target and the set of explanatory variables. 
The main intention of this study is to test the forecasting ability of ANN models in case of India VIX. Specifically, to build an ANN model which can predict the upwards or downwards movement of volatility as implied by India VIX close index for the next trading day. Historical India VIX data from January 2010 to January 2013 is analyzed using three layer architecture of the Artificial Neural Networks (ANN). The findings of the study suggest that for the given period under consideration, ANN models could forecast movement in the next trading day's volatility more efficiently when there is a downwards movement in comparison to the case when there is an upwards movement. The results support the view of VIX being an investor fear gauge. The results of this study are significant value addition to the trading decisions in the NIFTY Options contracts.

The organization of this paper is as follows. The next section (section 2) will provide a brief literature review on finance forecasting, volatility forecasting and artificial neural network. The section 3 discusses the artificial neural network, its architecture \& learning method which is followed by data $\&$ methodology used and modeling procedure. In section 4 , the findings and analysis part of the study have been covered. Finally, in the last section, conclusion and future directions for research have been discussed.

\section{RELATED WORKS}

In this section, review of the literature related to finance \& volatility forecasting will be done which will be followed by a review of literature on the application of neural networks in financial forecasting.

Forecasting the stock market has always been an area of interest of researchers. Different models have been constructed for this purpose. The models may be broadly classified into stochastic models and deterministic models. Recently, the stochastic models have gained importance. After formulating the model, the accuracy and the computation time plays an important role in selection of the solution method. The different solution methods are based on statistical methods (regression and time series models), optimization methods, numerical methods, simulation techniques like Monte Carlo Simulation and Soft Computing methods. Soft computing methods are preferred by the researchers for their level of accuracy with less time. Artificial Neural Network is a framework based on Soft Computing framework. Similarly different methods have been implemented to forecast the volatility of the stock market. The investors need to have a good forecast of the volatility in order to assess the risk in their portfolio. Coming to trading in derivatives, volatility is one of the most important factors. It is very important to know the volatility of the underlying asset from the present time to the expiry time of the underlying asset. Volatility also plays an important role in establishing the monetary policies, e.g. in the United States, the Federal Reserve explicitly takes into account the volatility of stocks, bonds, currencies, and commodities in establishing its monetary policy (Poon and Granger, 2003).

Engle (1993) forecasted volatility using different time series models. Kroner (1996) goes a little further and explains how volatility forecasts can be created and used. The various time series models used for this purpose are random walk, ARMA, ARIMA, ARCH, GARCH, EWMA (Poon and Granger,2003).

In some studies volatility was estimated as a stochastic variable. The important studies which used this concept to model and forecast volatility are Hull and White $(1987,1988)$ and Anderson \& Sorenson(1997). Some of the studies of this domain take simulation techniques as a solution to their model (Duffie and Singleton, 1993; Singleton, 2001; Danielson, 1994). Fridman and Harris (1998) had used numerical integration as tool in lieu of simulation in their study.

Black Scholes Model (1973) for option pricing is a wonderful example which establishes the relation between the price of an options and the market volatility and is used by almost each and every investor of the options market. Apart from the traditional commodity and commodity options, recently in many derivative instruments, volatility itself stands as the underlying asset. Thus in this scenario the volatility of volatility needs to be accounted in order to price these derivative instruments (Poon and Granger, 2003). Therein lies the need to forecast VIX.

Kumar (2010) examined the statistical properties of VIX and its relationship with the Indian Stock market and gave an insight about the predictive power forecasting future variances. Banerjee \& Kumar (2011) establishes a close relation between the implied volatility and VIX. The paper also discusses some applications of the VIX in trading. However only time series models have been applied for forecasting the volatility index (Majumdar and Banerjee, 2004; Degiannakis, 2008). The main objective of this study is to apply neural network models for forecasting the volatility index.

Neural network models originated from the work of McCulloch and Pitts in 1943 (Garson, 1998). These models were first time applied in stock market context for efficient market hypothesis validation by examining the accuracy of the forecasts made by neural network models on IBM stock's daily returns (White, 1988). A comprehensive review of literature of the application of the ANN models is beyond the scope of this study. However, the effort was put to include the most relevant studies related to forecasting index returns.

Neural network models were used in various studies to test their forecasting ability in many of the international stock markets. Some of these studies examined the forecasting ability of neural network models based on the statistical and financial performance measures while some other studies compared the forecasting performances of ANN models with that of statistical forecasting methods (Gencay, 1998; Kim and Chun, 1998; Lim and McNeils, 1998; Lam, 2004; Rodriguez, Torra and Andrada, 2005).

Kwong (2001) used neural networks as a forecasting tool and included historical financial data of 7 Australian firms in the study. He found only $48.23 \%$ average accuracy using neural networks which was worse than the accuracy of naive predictors of $53 \%$. Another similar study was conducted by Al-Hindi and Al-Hasan (2002). They selected 7 Saudi Arabian firms from different sectors to test the forecasting ability of neural networks on the stock prices of Saudi Arabian companies and found an efficient prediction ability with a neural network of 2-5-1 structure.

The interest in the applications of ANN in the area of finance and stock markets grew during early 1990s and ANN became one of the most explored prediction technique for stock index returns. Giles, Lawrence \&Tsoi (2001) applied the neural networks in their method to the prediction of daily foreign exchange rates, addressing difficulties with non-stationarity, overfitting, and unequal a priori class probabilities, and found significant predictability in comprehensive experiments covering 5 different foreign exchange rates. Their method 
correctly predicted the direction of change for the next day with an error rate of $47.1 \%$.

Kim (2006) applied genetic algorithm based artificial neural networks for stock market analysis of Korean Stock Price Index. Genetic algorithm (GA) was primarily used for instance selection in artificial neural networks. This approach was used to avoid the inconsistent and unpredictable performance of ANNs for noisy data. The results indicated that GA approach is a promising method for instance selection in ANN.

Diler (2003) developed a model for forecasting the direction of the ISE National-100 Index for the next day by using neural network algorithms. Technical indicators were used as inputs for the model and the model estimated the direction of the ISE National-100 Index for the next day at a rate of $60.81 \%$.

Pavilidis et. al. (2005) used unsupervised clustering and feedforward neural network to forecast the short run behaviour of the foreign exchange rates. They used the daily spot exchange rates of Euro against the Japanese Yen for their study.

In another application of neural networks, Nakamura (2005) studied usefulness of neural networks in forecasting the inflation. Results of this study showed neural networks outperforming univariate auto regressive models on US data of one to two quarters.

Furthermore, AVCI (2007) examined the forecasting power of the multilayer perceptron models for daily and seasonal returns of Istanbul Stock Exchange (ISE-100) index. The study found the forecasting performance of the model to be promising and provided directions for further improvements. Vashisth \& Chandra (2010) applied ANN for predicting stock returns in Nifty Index and found that ANN models could efficiently predict daily returns of Nifty Index.

\section{ARTIFICIAL NEURAL NETWORKS}

\section{$(\mathrm{ANN})$}

This section discusses the artificial neural networks, its architecture, learning of the ANN, dataset used for volatility forecasting and the modeling procedure.

In the last decade or so, the popularity of artificial neural networks has increased among the practitioners from a variety of disciplines like finance, medical sciences, engineering, social sciences, business etc. The main reason for the increase in the popularity is generally attributed to ANN's ability to handle very complex problems, datasets by following a simple and easy approach. ANNs have been found useful to solve a wide spectrum of complex problems originating from various disciplines. From the very start of ANN, the research community has given the high importance to ANN for its ability to manage the complicated issues with greater ease. The fundamental concepts of neural networks were derived from the Biological Neurons (Cajal, 1911) and for the first time, idea of artificial neural networks was introduced by McCulloch and Pitts in 1943. Although the inspiration of ANN came from the Biological neural networks, its architecture is characterized by applications of mathematics for analysis of complex problems.

\subsection{The Architecture of ANN}

In the past, a number of neural networks have been modeled and tested. These ANNs have generally followed either the view formed by biologists' microscopic observations or the view based on the mathematical analysis of the problem. The most commonly used structure of ANN has been depicted in the figure 1 below. This ANN consists of mainly three layersinput layer, hidden layer and the output layer. The layers may contain one or more nodes which have been represented by small circles in this figure. The flow of information between two nodes has been depicted by the lines joining one node to the other. The flow of the information is possible only in one direction, from input layer towards the output layer in this particular kind of ANN. The connections among nodes may be more complicated in other types of ANNs. The neural network is formed as a dense interconnection when a series of neurons of such types are put together.

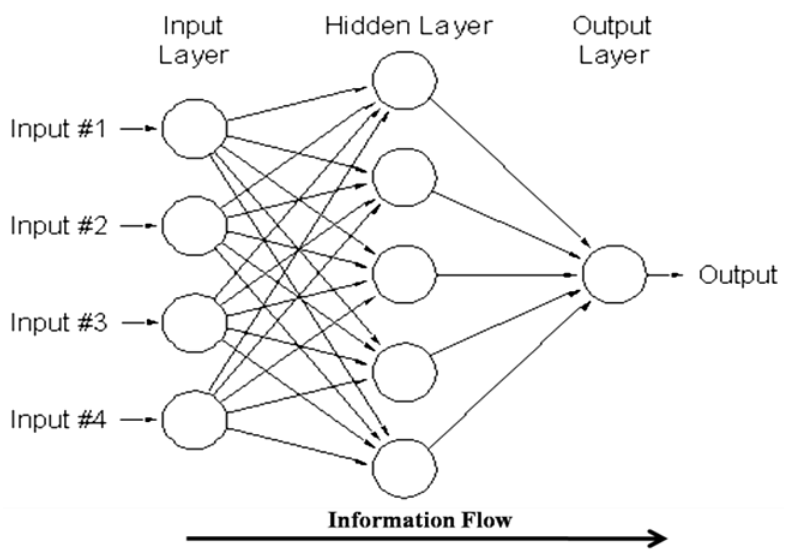

Fig 1: General Architecture of ANN

The mathematical architecture of an ANN is shown in the figure 2 .

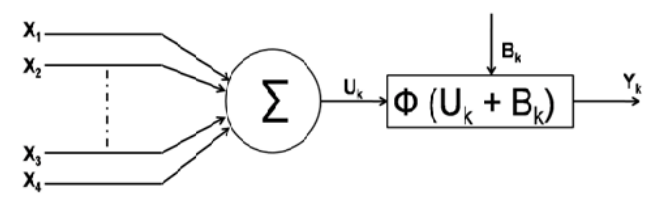

Fig 2: Mathematical Structure of ANN

It can be explained by the following mathematical formulation:

If $\mathrm{X}_{1}, \mathrm{X}_{2}, \mathrm{X}_{3}, \ldots, \mathrm{X}_{\mathrm{n}}$ are the input signals and $\mathrm{W}_{\mathrm{k} 1}, \mathrm{~W}_{\mathrm{k} 2}, \mathrm{~W}_{\mathrm{k} 3}$, ....., $\mathrm{W}_{\mathrm{kn}}$ are the synaptic weights, the induced local output $\left(\mathrm{U}_{\mathrm{k}}\right)$ is written as

$\mathrm{U}_{\mathrm{k}}=\mathrm{W}_{\mathrm{k} 1} \mathrm{X}_{1}+\mathrm{W}_{\mathrm{k} 2} \mathrm{X}_{2}+\mathrm{W}_{\mathrm{k} 3} \mathrm{X}_{3}+\ldots \ldots \ldots+\mathrm{W}_{\mathrm{kn}} \mathrm{X}_{\mathrm{n}}$.

And, the output of the neurons $\left(\mathrm{Y}_{\mathrm{k}}\right)$ is given by

$\mathrm{Y}_{\mathrm{k}}=\Phi\left(\mathrm{U}_{\mathrm{k}}+\mathrm{B}_{\mathrm{k}}\right)$

where $\Phi$ is the activation function and $B_{k}$ is the bias input.

The output of the neurons is controlled by two features: $B_{k}$ and $\Phi$ as shown in the figure 2 .

The bias input, $B_{k}$ acts as an amplifier and is assigned a value of 1 for positive amplification and a value of -1 for the negative amplification. The activation function, $\Phi$ controls the nature of the activation. It simply means that the property of the neurons is controlled by this function (Roy and Roy, 2008).

\subsection{The Learning of the ANN}

When constructing a neural network, making a decision on what the network will learn is an important factor. To find a solution for decision issues like when to buy or sell securities based on historical data or previous market trends or 
indicators are generally the objectives of these networks. Determining the right set of indicators and the relevant input data remains the main challenge and gathering enough input data for training the model appropriately comes next. Any new input data which cannot be explained by the existing network model has to be learnt by it. Therefore, an adjustment in the synaptic weights is done by the artificial neural network to accommodate the effect of the new input into the network for further learning. Such input data are said to be working as stimulant for the network. Feeding of more of such stimulating inputs to the network prepares it well to deal with unknown input set that are part of the problem space. This is the method used by ANN for learning. A variety of ANN models have been developed based on the different learning techniques used, ranging from single layer perceptron to SelfOrganizing Maps (SOMs) and many more (Kohonen, 1998)

A large number of ANN models have been developed by the researchers which can be generally classified into following two main categories depending on the type of learning method used by them- ANN with supervised learning techniques, and ANN with unsupervised learning techniques.

In ANN models with supervised learning techniques, learning is guided. In this type of ANN model, the output data along with the input data and their corresponding weights is provided to the model. The main focus of ANN remains to learn a mapping between inputs and outputs by simply adjusting the synaptic weights. In ANN models with unsupervised learning techniques, output data of any kind is not known. This type of ANN models try to classify the inputs by creating clusters of similar type inputs using some empirical or mathematical relationship.

\subsection{Data and Method}

This study aims to examine the ability of ANN models in forecasting the India VIX index. The daily data of the India VIX- a volatility index based on the index option prices of NIFTY have been used. The dataset consisted of daily opening, closing, high and low values of the index from January 2010 to January 2013.

To enable the ANN model forecast efficiently, various technical indicators were used to achieve a model fit. Total 16 indicators were used as input parameters in the ANN model out of the different indicators that are generally used in technical analysis. All these indicators are created based on the dataset consisting of daily opening, closing, high and low values of the India VIX index. The central idea is to include those indicators as input parameters in ANN model which might gauge or capture different patterns in trading of India VIX index to help predict the next trading day's close index.

First seven indicators are current day's open $(\mathrm{CO})$, high $(\mathrm{CH})$, low (CL) and close (CC) index values followed by previous day's high (PH), low (PL) and close (PC) index values. Next four input parameters were calculated using the simple moving average of the last (including the current day) 3 days (SMA3), 5 days (SMA5), 10 days (SMA10) and 15 days (SMA15)closing India VIX values. Average change in close index values for last five days (CHG5), change in close index values from previous day (CHG1) and change in index values from current day's open to close (CHG) are the next input parameters. The number of days before the next trading day (NDAYS) is the next indicator. Finally, a dummy variable representing the current day in Monday-Sunday (0-6) weekly sequence (DAY) was also included as an input parameter. Dependent variable or target variable is movement in next trading day's closing VIX index (MOV).
In this paper, while organizing the dataset for the ANN model, the concept of moving average window have been used. Therefore, whenever recently received data is included for the training of the ANN model, the oldest data is removed from the training set. The use of moving average window enables the ANN model to capture the environmental changes through the use of most recent data. The forecasting performance of neural network models can be analyzed in a continuous manner by utilizing this approach.

\subsection{Modeling Procedure}

Over the years, several ANN models have been used for forecasting research. This study followed the three layer (including one hidden layer) multilayer perceptron model with back-propagation algorithm as these models have been mathematically proved to be universal approximation for any continuous function. Also in the neural network research, multilayer perceptron model has grown to be a standard forecasting method. Over $80 \%$ of the research in the finance and stock markets is carried out using this model (Adya and Collopy, 1998). Efficient handling of a high degree of nonlinear problem space provides another advantage to the multilayer back-propagation network (Roy and Roy, 2008).

In this study, the back-propagation network (BPN) model has been used to predict the India VIX index. The BPN models built in this study consisted of 16 input parameters, 1 hidden layer and 1 output layer. One such model (model1) has been depicted in the figure 3 .

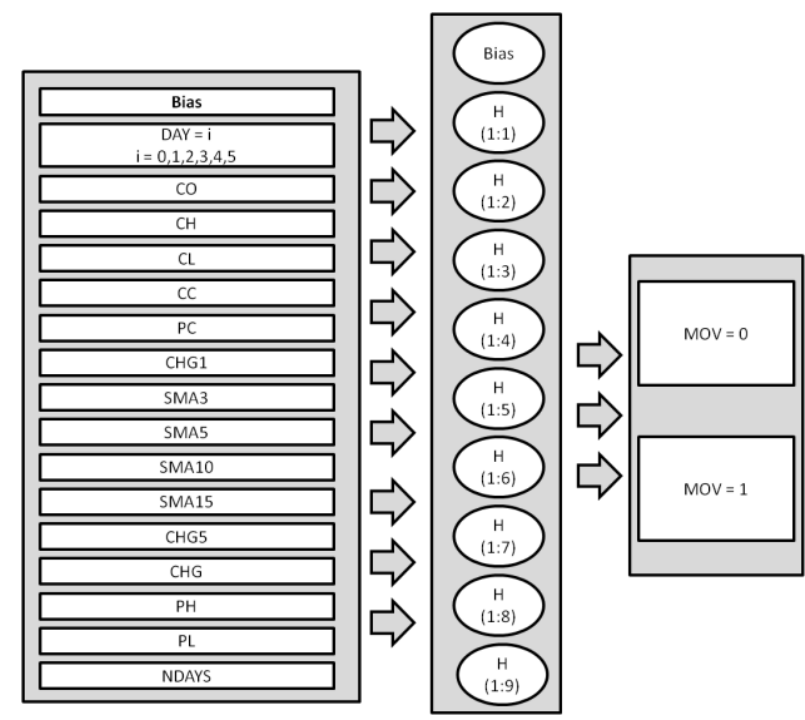

Fig 3: BPN model (model 1)

The Hyperbolic tangent function has been used as the activation function in this study and sum of squares error on the output end has been used for the purpose of calculation and rectification of output. The network was trained using the following approach: prediction is done for the movement of volatility closing index (upwards or downwards) for the next trading day based on the previous day's data point using the trained neural network.

In simple words, the ANN model of this study has been designed such that from the input of the $t^{\text {th }}$ day, the network will be forecasting the movement in the $(t+1)^{\text {th }}$ day's closing index. The ANN network was trained using a moving average window of 739 data points and was tested on 10 data points from 4 Jan 2013 to 16 Jan 2013. For each test, an ANN model was trained with a new set of 739 data points by leaving the oldest day's data out and adding the recent day's data. The 
trained model was then fed the data of very next day to forecast the movement of next trading day's VIX closing index. For example, an ANN model trained on the dataset from 22 Jan 2010 to 3 Jan 2013 was fed the data of 4 Jan 2013 to forecast the movement in the closing VIX index of 7 Jan 2013 (next trading day) relative to that of 4 Jan 2013. This process was repeated for all 10 tests. Details about all 10 models is shown in table 1 .

Table 1. Details about Training and Testing data

\begin{tabular}{|c|c|c|}
\hline $\begin{array}{c}\text { ANN } \\
\text { Model No. }\end{array}$ & $\begin{array}{c}\text { Dataset used for } \\
\text { training }\end{array}$ & $\begin{array}{c}\text { Dataset used for } \\
\text { testing }\end{array}$ \\
\hline 1 & 22 Jan 2010 - 3 Jan 2013 & 4 Jan 2013 \\
\hline 2 & 25 Jan 2010 - 4 Jan 2013 & 7 Jan 2013 \\
\hline 3 & 27 Jan 2010 - 7 Jan 2013 & 8 Jan 2013 \\
\hline 4 & 28 Jan 2010 - 8 Jan 2013 & 9 Jan 2013 \\
\hline 5 & 29 Jan 2010 - 9 Jan 2013 & 10 Jan 2013 \\
\hline 6 & 1 Feb 2010 - 10 Jan 2013 & 11 Jan 2013 \\
\hline 7 & 2 Feb 2010 - 11 Jan 2013 & 14 Jan 2013 \\
\hline 8 & 3 Feb 2010 - 14 Jan 2013 & 15 Jan 2013 \\
\hline 9 & 4 Feb 2010 - 15 Jan 2013 & 16 Jan 2013 \\
\hline 10 & 5 Feb 2010 - 16 Jan 2013 & 17 Jan 2013 \\
\hline
\end{tabular}

\section{RESULTS AND ANALYSIS}

The objective of this study is to map out a pattern in the India VIX indices which can help us forecast the future movements of the India VIX index. To achieve this goal artificial neural network have been used and not any of the other available alternatives like technical analysis and econometric modeling due to some basic limitations associated with these techniques. For example, Roy and Roy (2008) argued that using tools of technical analysis like Simple Moving Average (SMA) yield biased results if the data of a longer time period is used for the analysis instead of the data of a shorter period. They also argued that the patterns and the forecasting results about the prices/returns change if the data belonging to a shorter time period is considered for the analysis.

Neural networks doesn't face any such limitations, rather these models tend to forecast the movements in real sense. In this study, the dataset of a period of 3 calendar years ranging from January 2010 to January 2013 have been used to train and test the forecasting ability of ANN models. The classification results for all 10 trained models have been shown in the tables $2-11$.

Table 2. Classification results: model 1

\begin{tabular}{|lc|c|c|c|}
\hline \multirow{2}{*}{ Sample } & Observed & Down & Up & Percent \\
\cline { 3 - 5 } & & \multicolumn{3}{|c|}{ Porrect } \\
\hline Training & Down & 275 & 110 & $71.4 \%$ \\
& Up & 194 & 160 & $45.2 \%$ \\
& Overall Percent & $63.5 \%$ & $36.5 \%$ & $58.9 \%$ \\
\hline
\end{tabular}

Dependent Variable: MOV

Table 3. Classification results: model 2

\begin{tabular}{|cc|c|c|c|}
\hline \multirow{2}{*}{ Sample } & Observed & Down & Up & Percent \\
\cline { 2 - 5 } Correct
\end{tabular}

Table 3. Classification results: model 2

\begin{tabular}{|lc|c|c|c|}
\hline \multirow{2}{*}{ Sample } & Observed & Down & Up & Preent \\
\cline { 2 - 5 } & Correct \\
\hline Training & Down & 297 & 88 & $77.1 \%$ \\
& Up & 223 & 131 & $37.0 \%$ \\
& Overall Percent & $70.4 \%$ & $29.6 \%$ & $57.9 \%$ \\
\hline
\end{tabular}

Dependent Variable: MOV

Table 4. Classification results: model 3

\begin{tabular}{|cc|c|c|c|}
\hline \multirow{2}{*}{ Sample } & Observed & Down & Up & $\begin{array}{c}\text { Percent } \\
\text { Correct }\end{array}$ \\
\cline { 2 - 5 } Training & Down & 287 & 99 & $74.4 \%$ \\
& Up & 216 & 137 & $38.8 \%$ \\
& Overall Percent & $68.1 \%$ & $31.9 \%$ & $57.4 \%$ \\
\hline \multicolumn{3}{|c|}{ Dependent Variable: MOV }
\end{tabular}

Table 5. Classification results: model 4

\begin{tabular}{|cc|c|c|c|}
\hline \multirow{2}{*}{ Sample } & Observed & Down & Up & $\begin{array}{c}\text { Percent } \\
\text { Correct }\end{array}$ \\
\cline { 2 - 5 } Training & Down & 289 & 96 & $75.1 \%$ \\
& Up & 199 & 155 & $43.8 \%$ \\
& Overall Percent & $66.0 \%$ & $34.0 \%$ & $60.1 \%$ \\
\hline
\end{tabular}

Dependent Variable: MOV

Table 6. Classification results: model 5

\begin{tabular}{|rc|c|c|c|}
\hline \multirow{2}{*}{ Sample } & Observed & Down & Up & Percent \\
\cline { 3 - 5 } & & Correct \\
\hline Training & Down & 283 & 102 & $73.5 \%$ \\
& Up & 195 & 159 & $44.9 \%$ \\
& Overall Percent & $64.7 \%$ & $35.3 \%$ & $59.8 \%$ \\
\hline
\end{tabular}

Dependent Variable: MOV

Table 7. Classification results: model 6

\begin{tabular}{|cc|c|c|c|}
\hline \multirow{2}{*}{ Sample } & Observed & Down & Up & $\begin{array}{c}\text { Percent } \\
\text { Correct }\end{array}$ \\
\cline { 2 - 5 } Training & Down & 277 & 108 & $71.9 \%$ \\
& Up & 182 & 172 & $48.6 \%$ \\
& Overall Percent & $62.1 \%$ & $37.9 \%$ & $60.8 \%$ \\
\hline
\end{tabular}

Dependent Variable: MOV

Table 8. Classification results: model 7

\begin{tabular}{|cc|c|c|c|}
\hline \multirow{2}{*}{ Sample } & Observed & Down & Up & $\begin{array}{c}\text { Percent } \\
\text { Correct }\end{array}$ \\
\cline { 2 - 5 } Training & Down & 271 & 113 & $70.6 \%$ \\
& Up & 206 & 149 & $42.0 \%$ \\
& Overall Percent & $64.5 \%$ & $35.5 \%$ & $56.8 \%$ \\
\hline
\end{tabular}

Dependent Variable: MOV 
Table 12. Model 1 parameter estimates

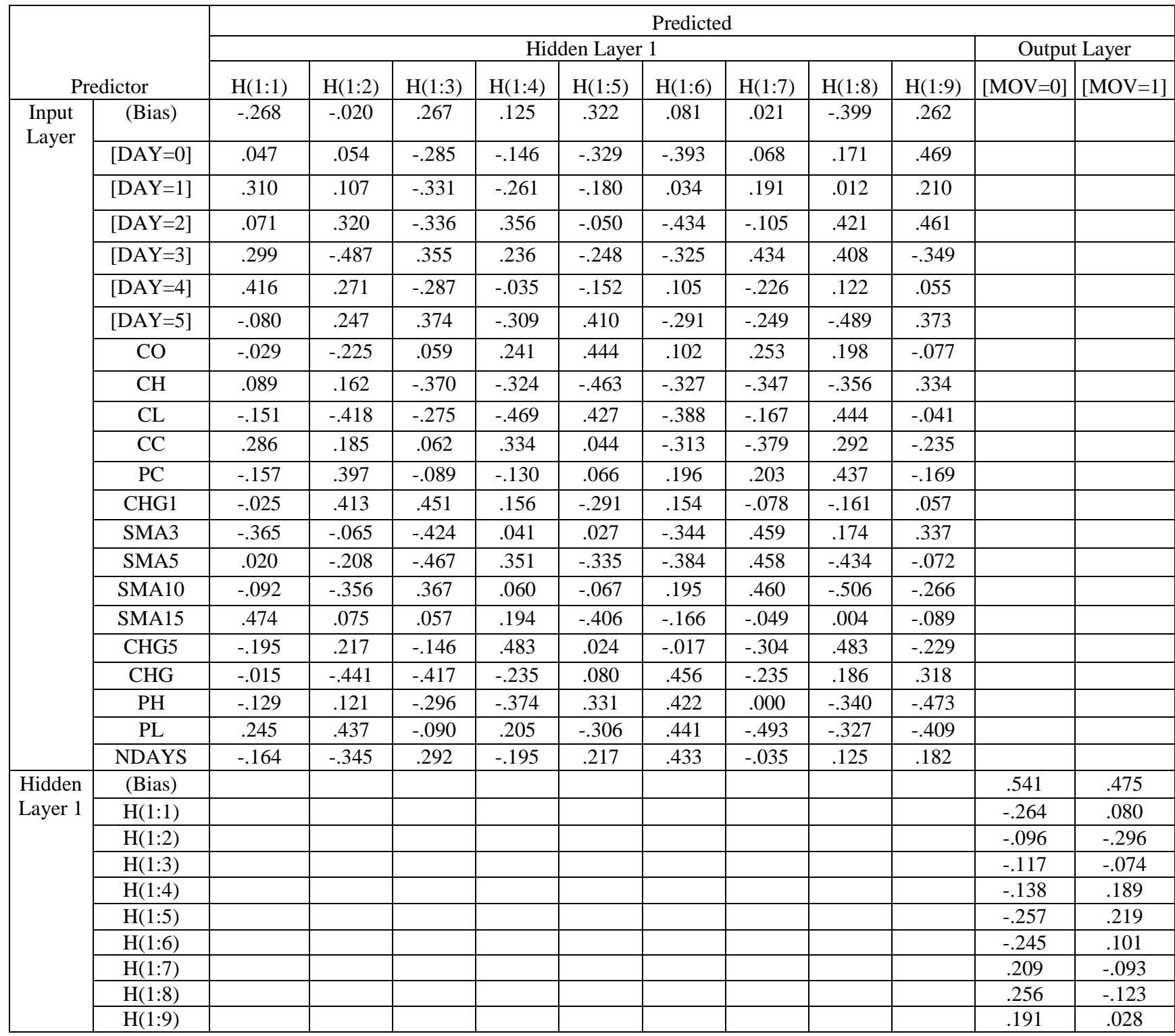

Table 9. Classification results: model 8

\begin{tabular}{|cc|c|c|c|}
\hline \multirow{2}{*}{ Sample } & Observed & Down & Up & Percent \\
\cline { 3 - 5 } & & \multicolumn{3}{|c|}{ Porrect } \\
\hline Training & Down & 271 & 114 & $70.4 \%$ \\
& Up & 188 & 166 & $46.9 \%$ \\
& Overall Percent & $62.1 \%$ & $37.9 \%$ & $59.1 \%$ \\
\hline
\end{tabular}

Dependent Variable: MOV

Table 10. Classification results: model 9

\begin{tabular}{|cc|c|c|c|}
\hline \multirow{2}{*}{ Sample } & Observed & Down & Up & $\begin{array}{c}\text { Percent } \\
\text { Correct }\end{array}$ \\
\cline { 2 - 5 } Training & Down & 294 & 91 & $76.4 \%$ \\
& Up & 196 & 158 & $44.6 \%$ \\
& Overall Percent & $66.3 \%$ & $33.7 \%$ & $61.2 \%$ \\
\hline
\end{tabular}

Dependent Variable: MOV
Table 11. Classification results: model 10

\begin{tabular}{|cc|c|c|c|}
\hline \multirow{2}{*}{ Sample } & Observed & Down & Up & $\begin{array}{c}\text { Percent } \\
\text { Correct }\end{array}$ \\
\cline { 2 - 5 } Training & Down & 268 & 117 & $69.6 \%$ \\
& Up & 173 & 181 & $51.1 \%$ \\
& Overall Percent & $59.7 \%$ & $40.3 \%$ & $60.8 \%$ \\
\hline
\end{tabular}

Dependent Variable: MOV

It can be observed from the results that the forecasting accuracy of all the 10 models is very much similar and hovers around $57-61 \%$. Similar results have been reported in terms of percentage prediction accuracy or variance explained in the target variable by other models in case of VIX. It can also be observed that prediction accuracy (69-77\%) across all 10 
ANN models is much higher for the downwards movement of VIX closing index in comparison to upwards movement of the same $(37-51 \%)$. The results support the existing view that VIX is an investor fear gauge as the ANN models are able to predict the downwards movement more accurately.

As first part of the analysis, each neural network was trained with 739 data points. One such trained model (model1) is shown in the figure 3. Parameters estimates of the model shown in the figure 3 are displayed above in table 12 .

The tables 13-22 show the details about the training results for all the 10 models.

Table 13. Model 1 Summary

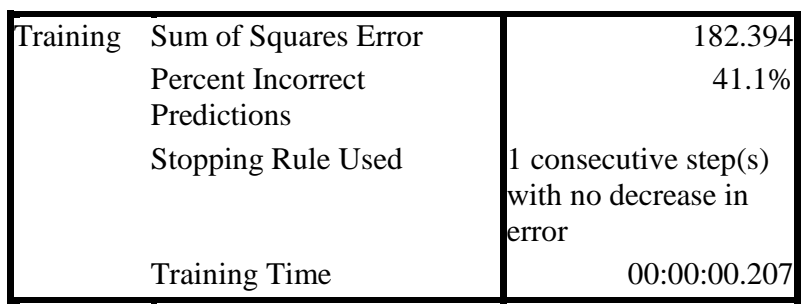

Dependent Variable: MOV

a. Error Computations are based on the training sample.

Table 14. Model 2 Summary

\begin{tabular}{|c|c|c|}
\hline \multirow[t]{3}{*}{ Training } & Sum of Squares Error & 180.544 \\
\hline & $\begin{array}{l}\text { Percent Incorrect } \\
\text { Predictions }\end{array}$ & $42.1 \%$ \\
\hline & Stopping Rule Used & $\begin{array}{l}1 \text { consecutive step(s) } \\
\text { with no decrease in } \\
\text { error }\end{array}$ \\
\hline & Training Time & 00:00:00.502 \\
\hline
\end{tabular}

a. Error Computations are based on the training sample.

Table 15. Model 3 Summary

\begin{tabular}{|c|c|c|}
\hline \multirow[t]{3}{*}{ Training } & Sum of Squares Error & 179.454 \\
\hline & $\begin{array}{l}\text { Percent Incorrect } \\
\text { Predictions }\end{array}$ & $42.6 \%$ \\
\hline & Stopping Rule Used & $\begin{array}{l}1 \text { consecutive step(s) } \\
\text { with no decrease in } \\
\text { error }\end{array}$ \\
\hline & Training Time & 00:00:00.473 \\
\hline
\end{tabular}

a. Error Computations are based on the training sample.

Table 16. Model 4 Summary

\begin{tabular}{|cl|r|}
\hline Training & Sum of Squares Error & 172.577 \\
& Percent Incorrect \\
& Predictions \\
& Stopping Rule Used & $39.9 \%$ \\
& $\begin{array}{l}\text { 1 consecutive step(s) } \\
\text { with no decrease in } \\
\text { error raining Time }\end{array}$ & $00: 00: 00.684$ \\
\hline
\end{tabular}

Dependent Variable: MOV

a. Error Computations are based on the training sample.
Table 17. Model 5 Summary

\begin{tabular}{|c|c|c|}
\hline \multirow[t]{4}{*}{ Training } & Sum of Squares Error & 177.680 \\
\hline & $\begin{array}{l}\text { Percent Incorrect } \\
\text { Predictions }\end{array}$ & $40.2 \%$ \\
\hline & Stopping Rule Used & $\begin{array}{l}1 \text { consecutive step(s) } \\
\text { with no decrease in } \\
\text { error }\end{array}$ \\
\hline & Training Time & 00:00:00.538 \\
\hline
\end{tabular}

Dependent Variable: MOV

a. Error Computations are based on the training sample.

Table 18. Model 6 Summary

\begin{tabular}{|c|c|c|}
\hline \multirow[t]{4}{*}{ Training } & Sum of Squares Error & 172.935 \\
\hline & Percent Incorrect & $39.2 \%$ \\
\hline & $\begin{array}{l}\text { Predictions } \\
\text { Stopping Rule Used }\end{array}$ & 1 consecutive step(s) \\
\hline & & $\begin{array}{l}\text { with no decrease in } \\
\text { error }\end{array}$ \\
\hline & Training Time & 00:00:00.623 \\
\hline
\end{tabular}

Dependent Variable: MOV

a. Error Computations are based on the training sample.

Table 19. Model 7 Summary

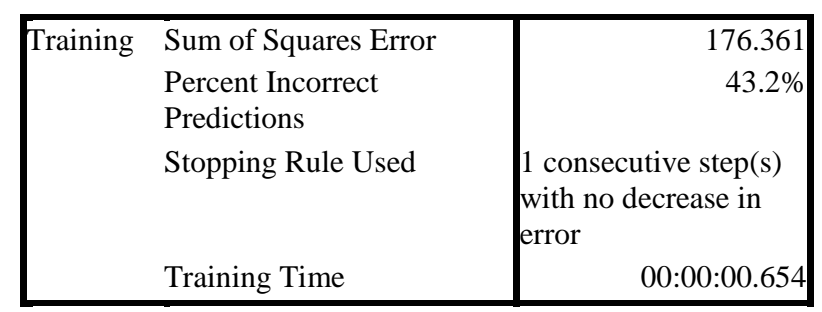

Dependent Variable: MOV

a. Error Computations are based on the training sample.

Table 20. Model 8 Summary

\begin{tabular}{|cl|r|}
\hline Training & Sum of Squares Error & 177.028 \\
& Percent Incorrect \\
& Predictions & $40.9 \%$ \\
& Stopping Rule Used & 1 consecutive step(s) \\
& with no decrease in \\
& Training Time & 00:00:00.661 \\
\hline
\end{tabular}

Dependent Variable: MOV

a. Error Computations are based on the training sample.

Table 21. Model 9 Summary

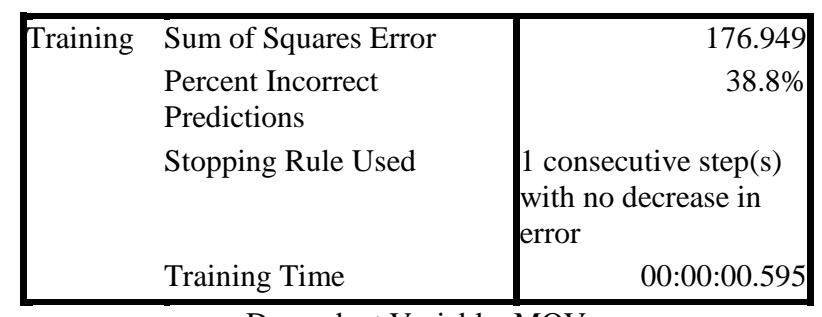

Dependent Variable: MOV

a. Error Computations are based on the training sample. 
Table 22. Model 10 Summary

\begin{tabular}{|cl|r|}
\hline Training & Sum of Squares Error & 172.426 \\
& Percent Incorrect \\
Predictions & $39.2 \%$ \\
& Stopping Rule Used & $\begin{array}{l}\text { 1 consecutive step(s) } \\
\text { with no decrease in } \\
\text { error c }\end{array}$ \\
& Training Time & 00:00:00.533 \\
\hline
\end{tabular}

Dependent Variable: MOV

a. Error Computations are based on the training sample.

It can be observed that sum of squares errors (172-182) and percent incorrect predictions (38-43\%) are nearly same across 10 models which means that the network is not overtrained and error made by the network while forecasting the results for the future data points will be similar in future predictions.

Next, ANN models were tested the trained for their ability to predict the index as per the details shown in table 1. The ANN models were fed with the test day's data to predict the closing index for the next trading day. The ANN model forecasted the closing index for the next day based on the data of previous (test) day's values. The same exercises were repeated to test the ANN model capabilities for rest of the test days. Testing results of ANN models are shown in table 23.

Table 23. Test classification results

\begin{tabular}{|lc|c|c|c|}
\hline \multirow{2}{*}{ Sample } & Observed & Down & Up & Percent \\
\cline { 2 - 5 } & & \multicolumn{3}{|c|}{ Porrect } \\
\hline Testing & Down & 4 & 1 & $80.0 \%$ \\
& Up & 2 & 3 & $60.0 \%$ \\
& Overall Percent & $60.0 \%$ & $40.0 \%$ & $70.0 \%$ \\
\hline
\end{tabular}

Dependent Variable: MOV

Since India VIX data is normalized, it is better to be used as a signal for upwards or downwards movement in the market volatility rather than the actual magnitude of increase or decrease in index values. It can be observed from the table 23 that overall prediction percentage of movements in the market volatility for test sample $(70 \%)$ is better than that of trained models $(\sim 59 \%)$. Also the prediction accuracy for downwards movements in volatility $(80 \%)$ is much higher than that of upwards movements $(60 \%)$.

\section{CONCLUSION AND FUTURE DIRECTIONS}

The applications of artificial neural networks have been garnering attention of the researchers from many disciplines including the finance area. ANN models have been proved to be very promising in the finance applications especially in forecasting the prices, returns and indices. ANN's ability to handle the complicated data with much ease has proved to be the main reason for producing the good results for such research. The back-propagation technique of the neural network has provided excellent results. ANN models' success also depends on the selection of key explanatory variables which help determine the structure of the final model as well as the interconnections with output variables.

In this study, the forecasting ability of ANN models have been tested in the India VIX index. The effectiveness of the ANN models in forecasting the India VIX index has been examined in this study. To achieve this goal, the daily data from the India VIX index ranging from January 2010 to January 2013 was obtained and the ANN models were trained using many sets of data. After training the neural network, it is fed with a single data point to forecast the movement in index values for next trading day. The trained model results show a much better prediction accuracy of ANN models for the downwards movement of VIX closing index in comparison to upwards movement of the same. The forecasted results for test days by ANN models performed better than the overall prediction percentage of trained models.

The current study examined the prediction accuracy of the ANN models in forecasting the VIX index values, but the scale and scope of the study may be limited to the time period considered in the study and India index respectively. Therefore, findings of this study might not be generalized before doing further research considering other country indices and longer time period.

\section{REFERENCES}

[1] Adya M, \& Collopy F. 1998. How Effective are Neural Networks at Forecasting and Prediction? A Review and Evaluation. Journal of Forecasting 17(5-6): 481-495.

[2] Al-Hindi HA, Al-Hasan ZF. 2002. Forecasting Stock Returns with the Neural Network Models. Journal of King Saud University 14(1): 65-81.

[3] Andersen TG, Sorensen BE.1997. GMM and QML Asymptotic Standard Deviations in Stochastic Volatility Models, Journal of Econometrics 76: 397-403.

[4] Avci E. 2007. Forecasting Daily and Seasonal Returns of the ISE-100 Index with Neural Network Models. Dogus University Journal 8(2): 128-142.

[5] Bannerjee, A. \& Kumar, R. (2011). Realized Volatility and India VIX. IIM Calcutta working paper series no 688 .

[6] Black F, Scholes M. (1973). The Pricing of Options and Corporate Liabilities. The Journal of Political Economy 81(3): 637-654.

[7] Blair BJ, Poon S-H, Taylor SJ. 2001. Forecasting S\&P100 Volatility: The Incremental Information Content of Implied Volatilities and High-Frequency Index Returns. Journal of Econometrics 105: 5-26.

[8] Cajal R. S. (1911). Histology of the nervous system of man and vertebrates. New York: Oxford University Press.

[9] Danielsson J. 1994. Stochastic Volatility in Asset Prices: Estimation with Simulated Maximum Likelihood. Journal of Econometrics 64: 375-400.

[10] Degiannakis S. 2008. Forecasting VIX. Journal of Money, Investment and Banking 4: 5-19.

[11] Degiannakis S, Floros C. 2010. VIX Index in Interday and Intraday Volatility Models. Journal of Money, Investment and Banking 13: 21-26.

[12] Diler AI. 2003. Forecasting the direction of ISE National-100 index by neural networks backpropagation algorithm. ISE Review 7(25-26): 65-81. 
[13] Duffie D, Singleton KJ.1993. Simulated Moments Estimation of Markov Models of Asset Prices. Econometrica 6: 929-52.

[14] Engle RF. 1993. Statistical Models for Financial Volatility. Financial Analysts Journal. 49(1): 72-78.

[15] Fridman M., Harris L. 1998. A Maximum Likelihood Approach for Non Gaussian Stochastic Volatility Models. Journal of Business and Economic Statistics 16: 284-91.

[16] Garson GD. 1998. Neural Networks: An Introductory Guide for Social Scientists. London: Sage.

[17] Gencay R. 1998. Optimization of Technical Trading Strategies and the Profitability in the Stock Markets. Economic Letters 59(2): 249-254.

[18] Giles CL, Lawrence S, Tsoi AC. 2001. Noisy Time Series Prediction using Recurrent Neural Networks and Grammatical Inference. Machine Learning 44: 161-183.

[19] Hull J, White A. 1987. The pricing of options on assets with stochastic volatilities. Journal of Finance 42(2): 281-300.

[20] Hull J, White A. 1988. An Analysis Of The Bias In Option Pricing Caused By A Stochastic Volatility. Advances in Options and Futures Research 3: 27-61.

[21] Kim SH, Chun SH. 1998. Graded Forecasting Using Array of Bipolar Predictions: Application of Probabilistic Neural Networks to a Stock Market Index. International Journal of Forecasting, 14(3): 323-337.

[22] Kim KJ. 2006. Artificial Neural Networks with Evolutionary Instance Selection for Financial Forecasting. Expert System Applications, Vol.30, No. 3, pp.519-526.

[23] Kohonen T.1998. The self-organizing map. Neurocomputing 21: 1-6.

[24] Kroner KF.1996. Creating and using volatility forecasts. Derivatives Quarterly 3(2): 39-53.

[25] Kwong, C. K. 2001. Financial Forecasting Using Neural Networks or Machine Learning Techniques. http://www.innovexpo.itee.uq.edu.au/2001/projects/s804 018/index.html [19 January 2013].

[26] Lam M. 2004. Neural Network Techniques for Financial Performance Prediction: Integrating Fundamental and Technical Analysis. Decision Support Systems, 37(4):567-581.

[27] Lim GC, McNelis PD. 1998. The Effect of the Nikkei and the S\&P on the All- Ordinaries: A Comparision of
Three Models. International Journal of Finance and Economics 3(3): 217-228.

[28] Majumdar U, Banerjee A. 2004. VIX Forecasting. Social Science Research Network, Working Paper id-533583.

[29] McCulloch WS, Pitts W.1943. A logical calculus of the ideas immanent in nervous activity. The Bulletin of Mathematical Biophysics 5(4):115-133.

[30] Nakamura E. 2005. Inflation forecasting using a neural network. Economics Letters. 86(3) 373-378.

[31] Pavlidis NG, Tasoulis DK, Plagianakos VP, Nikiforidis G \& Vrahatis MN.2005. Spiking neural network training using evolutionary algorithms. International Joint Conference on Neural Networks (IJCNN 2005). IEEE: 2190-2194.

[32] Poon SH, Granger CWJ. 2003. Forecasting Volatility in Financial Markets: A Review. Journal of Economic Literature 41 (2): 478-539.

[33] Rodriguez JV, Torra S, Andrada FJ. 2005. STAR and ANN models: forecasting performance on the Spanish Ibex-35 stock index. Journal of Empirical Finance 12(3): 490-509.

[34] Roy P, Roy A. 2008. Forecasting Daily Returns of Nifty Index - Using the Method of Artificial Neural Network. Forecasting Financial Markets in India (FFMI) 2008 Conference Proceedings: 787-800.

[35] Singleton K.2001. Estimation of Affine Asset Pricing Models Using the Empirical Characteristic Function. Journal of Econometrics 102:111-141.

[36] The CBOE Volatility Index- VIX. http://www.cboe.com/micro/vix/vixwhite.pdf [12 December 2012]

[37] Vashisth R, Chandra A. 2010. Predicting stock returns in Nifty index: An application of artificial neural network. International Research Journal of Finance and Economics 49: 15-24.

[38] White H. 1988.Economic Prediction Using Neural Networks: The Case of IBM Daily Stock Returns. Proceedings of the Second Annual IEEE Conference on Neural Networks, II:451-458.

[39] White paper on India VIX http://www.nseindia.com/content/vix/white_paper_India VIX.pdf [12 December 2012]

[40] Xin M. 2011. The VIX Volatility Index. uu.divaportal.org/smash/get/diva2:417612/FULLTEXT0 1 [19 January 2013]. 